\title{
Wheat Bran Hydrolysate Culture Medium Design for Talaromyces Purpureogenus CFRM02 Pigment Production and Colour Characteristics
}

\section{Sujit Das}

CSIR-CFTRI: Central Food Technological Research Institute CSIR

\section{Saritha Gopal Pandit}

CSIR-CFTRI: Central Food Technological Research Institute CSIR

Mohan Dhale ( $\sim$ dhalemohan@yahoo.com)

CSIR-CFTRI: Central Food Technological Research Institute CSIR https://orcid.org/0000-0003-23181361

\section{Research Article}

Keywords: Wheat bran hydrolysate, T. purpureogenus, Pigment, Xylose

Posted Date: September 1st, 2021

DOl: https://doi.org/10.21203/rs.3.rs-840095/v1

License: (9) This work is licensed under a Creative Commons Attribution 4.0 International License.

Read Full License

Version of Record: A version of this preprint was published at BioEnergy Research on January 11th, 2022. See the published version at https://doi.org/10.1007/s12155-021-10368-z. 


\section{Abstract}

Wheat bran hydrolysate (WBH) in combination with carbon and nitrogen was utilised as substrate for pigment production by Talaromyces purpureogenus CFRM02. Pigment yield was significantly increased ( $\approx 3$ fold: OD units and $\approx 2$ fold: $a^{*}$ value) by xylose supplementation with WBH compared to other carbon sources. Whereas $1 \%$ xylose supplementation increased pigment production (1.57 \pm 0.05 OD Units and $49 \pm 1.62 a^{*}$ value). Pigment yield was low when WBH supplemented with $0.3 \%$ nitrogen sources. However significant increase $\left(\approx 2-2.5\right.$ fold, OD units and $a^{*}$ value) was observed, when yeast extract $(1.2 \%)$, nitrate of sodium (1.2\%) and potassium (1.6\%) were supplemented. Accordingly, 16 WBH media were designed by supplementing carbon and nitrogen. Interestingly the pigment production was significantly increased (1.59 OD units and $32 a^{*}$ value) in the medium supplemented with $4 \%$ carbon and 0.9-1.2\% nitrogen. T. purpureogenus CFRM02 was able to co-utilize xylose, fructose and glucose in WBH medium. The CIE Lab values indicated that, pigment characteristics differed significantly among the media. Apparently, T. purpureogenus CFRM02 possess alternative gene(s) or pathway(s) for xylose metabolism and channelled towards pigment biosynthesis. Comparative results revealed that, $1 \%$ xylose supplementation to WBH makes the fermentation process economically competitive for pigment production.

\section{Introduction}

Pigments have a broad range of application in food industries, that includes their utilization as additives, bioactives, and colour intensifiers [20-22]. Undesirable health effects upon excessive consumption of synthetic pigments have encouraged research on pigments from natural sources [1]. The production of natural pigments from microorganisms is highly desirable due to their controlled condition of growth, yeild and health benefit [12]. The fungi, yeasts and bacteria are known to produce pigment molecules like carotenoids, polyketides, azophilones, melanins, quinones, flavins, prodigiosins, monascins, violacein or indigo $[4,29]$. Among microorganisms, the fungi like Monascus, Paecilomyces and Penicillium/Talaromyces are highly researched because of high yield of pigments [2],[22]. The water solubility characteristics $[7,13]$ of these pigments increased their demand to produce in industrial scale. Because the water solubility conditions of pigment is being crucial for application in food industries $[6$, 13]. While the presence of mycotoxins have restricted from commercialization and utilization as food colorant $[6,15]$.

However, studies have identified that, Monascus-like red pigments produced by some species of Penicillium or Talaromyces [31]. Species of Talaromyces like T. purpurogenus, T. purpureogenus, T. marneffei, T. albobiverticillius and T. minioluteus secrete large amounts of red pigment [13]. The genus Talaromyces/Penicillium has gained more attention at industrial scale, as a cell factory for the process of pigment production [10,17, 30]. Like Monascus pigments, Talaromyces pigments possess a wide range of biological activities like antioxidant, antibacterial, and their safety efficacy was proven and considered as industrially important in the food industry owing to lack of mycotoxin production[21, 22]. The 
application these pigments have been reported in textiles for dyeing purpose [8]. Even though many Talaromyces spp. are known to produce red pigments, but only $P$. oxalicum has been used on an industrial scale to produce food colourant [5].

To create the sustainable industry scale fermentation process, identification of low-cost substrate is of particular interest to maximize pigment yields $[18,23,25]$. There are few reports on the production of Talaromyces pigment utilising various agro substrates. The corncob, broken wheat, orange peels, brown rice and cassava waste and seasame cake. Hydrolysates derived from these lignocellulosic materials generally contain a mixture of carbohydrates pentoses and hexoses [19]. Hence, it is necessary to understand the capability of microorganism to co-utilize pentoses and hexoses in order to maximize process on the produced pigmented molecules. It is also that, growth and pigment production in Talaromyces is profoundly affected by media components like carbon and nitrogen sources [17]. Whereas there are no report on the utilization of wheat bran hydrolysate (WBH) for pigment production and deal primarily with the color characteristics of derivatives. The present study aimed to utilize WBH as a substrate, supplemented with carbon and nitrogen for pigment production by T. purpureogenus CFRM02 and analysis of color characteristics.

\section{Materials And Method \\ 2.1 Material}

The culture media potato dextrose agar (PDA), potato dextrose broth (PDB), peptone, yeast extract and sugars were obtained from Hi-Media Laboratories, Mumbai, India for cultivation of T. purpureogenus CFRM02. Sodium nitrate and potassium nitrate were obtained from SRL Chemical Mumbai, India. The wheat bran (WB) was obtained from the Flour Milling Backing and Confectionary Technology Department, CFTRI, Mysore. T. purpureogenus CFRM02 culture [4] was maintained on PDA at $4^{\circ} \mathrm{C}$.

\subsection{Inoculum preparation}

Inoculum was prepared from $7-8$ day old sporulating slant by adding $(8 \mathrm{ml})$ sterile saline $(0.8 \%)$ containing $0.05 \%$ SDS. The spores were gently disturbed without damaging the agar. One $\mathrm{ml}$ spore suspension was transferred to a sterile Erlenmeyer's flask containing the growth medium either solid-state fermentation or submerged fermentation.

\subsection{Solid State Fermentation}

The solid-state fermentation media was prepared by adding distilled water to the Erlenmeyer's flasks containing $10 \mathrm{~g}(\mathrm{w})$ of WB. The moisture condition was adjusted by varying the volume (v) of distilled water $10 \mathrm{ml}(1: 1), 20 \mathrm{ml}(1: 2)$ and $30 \mathrm{ml}(1: 3 \mathrm{w} / \mathrm{v})$. These flasks were autoclaved at $121^{\circ} \mathrm{C}$ for $15 \mathrm{~min}$. After cooling, inoculated with $1 \mathrm{ml}$ of spore suspension $\left(\sim 1.93 \times 10^{6}\right)$ and kept for incubation (Adolf Khuner Therm-Lab, Switzerland) at $30^{\circ} \mathrm{C}$ for 10 days.

\subsection{Preparation of WBH}


The WHB was prepared by acid hydrolysis. The wheat bran $100 \mathrm{~g}$ was added to the 1 litre distilled water containing $0.25 \% \mathrm{H}_{2} \mathrm{SO}_{4}$. This was autoclaved at $121^{\circ} \mathrm{C}$ for $15 \mathrm{~min}$. After cooling, filtered through muslin cloth and stored at $-20^{\circ} \mathrm{C}$ in dark for further use. The $\mathrm{pH}$ of filtrate was adjusted prior to the inoculation.

\subsection{Submerged fermentation}

The $250 \mathrm{~mL}$ Erlenmeyer flask containing $100 \mathrm{~mL}$ of the culture medium were autoclaved at $121^{\circ} \mathrm{C}$ for 15 min and inoculated with $1 \mathrm{ml}$ of spore suspension. The initial $\mathrm{pH}$ of the medium was adjusted to 5.5 by adding $0.1 \mathrm{~N} \mathrm{NaOH}$ or $0.1 \mathrm{~N} \mathrm{HCL}$ prior to autoclave. The culture flasks were illuminated 12 hour day and night condition at $30^{\circ} \mathrm{C}$ for 10 days at $110 \mathrm{rpm}$ on rotary shaker (Adolf Khuner Therm-Lab, Switzerland). To determine the dry biomass, whole flasks cultures were poured through pre-dried $\left(100^{\circ} \mathrm{C}\right)$ reweighed Whattman No.1 filter paper. Retained mycelia material was washed with distilled water then ethanol until colourless and dried at $100^{\circ} \mathrm{C}$ to constant weight (48h).

\subsection{Culture media formulation}

The WBH obtained by acid hydrolysis was used for fermentation process as, i) WBH without nutrient supplementation, ii) WBH supplemented with carbon sources, iii) WBH supplementation adjusted to a xylose concentration, iv) WBH supplemented with nitrogen sources v) WBH adjusted to nitrogen concentrations, vi) WBH supplemented with adjusted carbon and nitrogen sources. A synthetic PDB was used as a control.

\subsection{Carbon source supplementation}

Six different carbon sources (glucose, fructose, sucrose, lactose, maltose and xylose) were supplemented to the WBH. One gram of each carbon source was added the flasks containing WBH. The flask containing only WBH without carbon sources was prepared for comparison as control. The medium was autoclaved and inoculated with $1 \mathrm{ml}$ spore suspension to each flask. These flasks were kept in rotary shaker incubator at $30^{\circ} \mathrm{C}, 120 \mathrm{rpm}$ for 10 days. Further, the optimum concentration of xylose was evaluated for the pigment production. Accordingly, various concentration of xylose $(1-4 \%)$ was added to the WB hydrolysate and cultured as above.

\subsection{Nitrogen source supplementation}

Five different nitrogen sources such as inorganic $\left(\mathrm{KNO}_{3}, \mathrm{NH}_{4} \mathrm{NO}_{3}\right.$ and $\left.\mathrm{NaNO}_{3}\right)$ and organic (peptone and yeast extract) were used for the media formulation. To the each Erlenmeyer's flask containing $100 \mathrm{ml}$ of WBH medium $0.3 \mathrm{gm}$ of nitrogen sources was added individually. After autoclave one $\mathrm{ml}$ of spore suspension was added to each flask. These flasks were kept in rotary shaker incubator at $30^{\circ} \mathrm{C}, 120 \mathrm{rpm}$ for 10 days. Further four different concentration (0.3-1.2\%) of yeast extract and $\mathrm{NaNO}_{3}$ were added to the WBH (Table 2) and cultured under submerged fermentation condition as described above.

\subsection{Combined effect of carbon and nitrogen}


The combination of carbon and nitrogen sources presented in Table 3 for the optimization of pigment yield. The above described submerged fermentation culture conditions were followed.

\subsection{Pigment quantification and colour analysis}

Pigment production was quantified after culture broth was filtered through Whatman No. 1 filter paper. The culture filtrates were directly used for quantification of pigment after appropriate dilution. The absorbance was recorded (UV-Visible 2450, Shimadzu Spectrophotometer, Japan) at $494 \mathrm{~nm}$ to quantify the pigments as absorption units $\left(\mathrm{OD} / \mathrm{AU} \mathrm{mL}^{-1}\right)$ [3]. The colour values were measured in accordance with $\mathrm{CIE} L^{*}, a^{*}, b^{*}$ colour measuring system. The Lightness $\left(L^{*}\right)$, redness $\left(+\mathrm{ve} a^{*}\right)$, and yellowness $\left(+\right.$ ve $\left.b^{\star}\right)$ values of culture filtrate were estimated using colour measuring system. The samples were analysed by placing in the port of 1-inch diameter (Lab Scan XE Hunter Lab Instruments, Virginia, USA). Appropriate control and blank were maintained for quantification and colour analysis [21]. The chroma $\left(C^{*}\right)$ and hue angle $\left(h^{*}\right)$ were calculated by following equations.

$C^{*}=\sqrt{a^{* 2}+b^{* 2}}(\mathrm{i})$

$h^{*}=\tan ^{-1}\left(b^{*} / a^{*}\right)(\mathrm{ii})$

\subsection{Statistical analysis}

Data were expressed as the mean \pm standard deviation of triplicate measurements. Results were processed by 1-way analysis of variance (ANOVA). A Duncan multiple range test was used to determine significant differences. Differences at $P<0.05$ were considered as significant.

\section{Results And Discussion}

Pigment producing microorganisms have gained significant attention due to the existing genetic diversity [28] and various industrial application. Whereas filamentous fungi are more attractive due to their potency to produce wide range of pigments [11]. The researches have focused their attention on process optimization for the production of pigments by Talaromyces spp [16]. Hence developing a new bioprocess requires several steps that includes designing and feasible optimizing process conditions to achieve high yields, using low cost fermentative substrate like wheat bran and its hydrolysate (WBH).

\subsection{Solid-state fermentation}

It was observed after 10 days of solid-state fermentation on WB at $30^{\circ} \mathrm{C}$, T. purpureogenus CFRM02 culture with deep green spores. The production of red colour pigment was negligible under various concentration (w/v) of moisture condition (Fig S1). Similarly, the pigment production by Penicillium sp was less in solid-state fermentation compared to submerged fermentation [3]. Kantifedaki et al [10] have also reported lower level of pigment production by P. purpurogenum CBS 113139 during solid-state 
fermentation using orange peel waste. Moreover, the medium used for fermentation process significantly affects the product yield in terms of biomass and pigment. It was confirmed that solid-state fermentation is not appropriate to produce T. purpureogenus CFRM02 pigment by utilizing WB.

\subsection{Submerged fermentation}

Consequently, submerged fermentation conditions were adopted to produce T. purpureogenus CFRM02 pigment in higher quantities. It was observed that the $\mathrm{pH}$ plays an essential role for the production of secondary metabolites and biomass yield [30]. The fungus grown in the PDB medium at different $\mathrm{pH}$ condition (Fig S2) has produced more red pigment $(0.362 \pm 0.00 \mathrm{OD}$ units $/ \mathrm{ml})$ at $\mathrm{pH} 6$ and $8(0.346 \pm 0.03$ $\mathrm{OD}$ units $/ \mathrm{ml})$. Even though the $\mathrm{OD}$ value $(0.552 \pm 0.05 \mathrm{OD}$ unit $/ \mathrm{ml})$ of the culture broth was higher at $\mathrm{pH}$ 10 , the pigment was not produced (Fig S2). The higher OD values of culture broth of $\mathrm{pH} 10$ was due to the interference of the other metabolites produced during the growth. This was evidenced by the analysis of T. purpureogenus CFRM02 culture broth containing pigment through UV-visible spectra and CIE Lab colour values. The prominent peak at $494 \mathrm{~nm}\left(\lambda_{\text {max }}\right)$ was observed in the spectrum of the culture broth of $\mathrm{pH} 6$ and 8 (Fig S2). Further the CIE Lab colour values for $\mathrm{pH} 6$ and 8 in terms of redness ( $a^{*}$ value) were $16.32 \pm 1.40$ and $11.65 \pm 1.82$ respectively. The biomass production was ranging between $(0.263 \pm 0.02)$ to $(0.377 \pm 0.06)$. Even though the higher biomass yield was observed at $\mathrm{pH} 10$, the pigment production was not increased significantly. Similarly, the temperature also affect the production of secondary metabolites. The higher pigment production was observed in the culture medium grown at $30^{\circ} \mathrm{C}$ (Fig S3). Similar studies with Monascus spp., Penicillium spp., Talaromyces spp. the optimal pH was found to be 5.5-6.5 and optimal temperature was $24-30^{\circ} \mathrm{C}$ for pigment production [30]. Accordingly for further cultivation of fungus on WBH medium and other nutrient supplementation, the $\mathrm{pH}$ and temperature was adjusted to 6 and $30^{\circ} \mathrm{C}$ respectively.

\subsection{Cost effective medium}

The production of pigments through microbial fermentation process using the commercially available media is expensive process. Hence, the development of a cost-effective bioprocess is essential for the production of $T$. purpureogenus CFRM02 pigment by using wheat bran as waste raw material. The main carbohydrate in WBH comprises starch, hemicellulose and cellulose [26]. It is also that, the pigment production in Penicillium sp was influenced by the presence of nitrogen in the medium [17]. Accordingly, the study was designed in four tasks. Initially, the WBH was evaluated with addition of individual carbon and nitrogen source after acid hydrolysis (Tables 1 and 2). The conditions of xylose levels and combination of $\mathrm{C} / \mathrm{N}$ were evaluated to obtain a liquor to be used as a fermentation medium. 
Table 1

Effect of carbon and xylose concentration supplementation to WBH medium on T. purpureogenus CFRM02 pigment characteristics and the CIELAB value.

\begin{tabular}{|c|c|c|c|c|c|c|}
\hline \multirow[t]{2}{*}{ Media } & & $\angle$ lightness & a value & $b$ value & $\begin{array}{l}h \text { hue } \\
\text { angle }\end{array}$ & c chroma \\
\hline & WBH & $\begin{array}{l}78.77 \pm \\
2.21^{\mathrm{a}}\end{array}$ & $\begin{array}{l}7.38 \pm 1.38 \\
b\end{array}$ & $\begin{array}{l}27.22 \pm \\
1.11 \mathrm{ab}\end{array}$ & $\begin{array}{l}74.87 \pm \\
2.35^{d}\end{array}$ & $\begin{array}{l}28.22 \pm \\
1.33^{a}\end{array}$ \\
\hline \multirow[t]{5}{*}{$\begin{array}{l}\text { Carbon } \\
\text { Source (1\%) }\end{array}$} & Glu & $\begin{array}{l}84.59 \pm \\
3.44 \mathrm{bc}\end{array}$ & $\begin{array}{l}11.56 \pm \\
0.69 \mathrm{e}\end{array}$ & $\begin{array}{l}26.26 \pm \\
1.05^{a}\end{array}$ & $\begin{array}{l}66.26 \pm \\
0.43^{a}\end{array}$ & $\begin{array}{l}28.69 \pm \\
1.24^{a}\end{array}$ \\
\hline & Fru & $\begin{array}{l}86.13 \pm \\
3.32 \mathrm{bc}\end{array}$ & $\begin{array}{l}8.25 \pm 0.64 \\
\mathrm{bc}\end{array}$ & $\begin{array}{l}28.48 \pm \\
0.82^{b}\end{array}$ & $\begin{array}{l}73.84 \pm \\
1.38 \mathrm{~cd}\end{array}$ & $\begin{array}{l}29.66 \pm \\
0.75^{a}\end{array}$ \\
\hline & Lac & $\begin{array}{l}81.57 \pm \\
2.06 \mathrm{ab}\end{array}$ & $\begin{array}{l}10.08 \pm \\
0.37 \mathrm{de}\end{array}$ & $\begin{array}{l}28.03 \pm \\
1.03 \mathrm{ab}\end{array}$ & $\begin{array}{l}70.21 \pm \\
0.39^{b}\end{array}$ & $\begin{array}{l}29.79 \pm \\
1.08^{a}\end{array}$ \\
\hline & Mal & $\begin{array}{l}85.57 \pm \\
1.69 \mathrm{bc}\end{array}$ & $\begin{array}{l}9.33 \pm 0.35 \\
c d\end{array}$ & $\begin{array}{l}27.47 \pm \\
0.62 a b\end{array}$ & $\begin{array}{l}71.24 \pm \\
0.30 \mathrm{bc}\end{array}$ & $\begin{array}{l}29.01 \pm \\
0.70^{a}\end{array}$ \\
\hline & Suc & $\begin{array}{l}88.11 \pm \\
1.53^{d}\end{array}$ & $\begin{array}{l}5.30 \pm 1.13 \\
\mathrm{a}\end{array}$ & $\begin{array}{l}27.26 \pm \\
1.58 \mathrm{ab}\end{array}$ & $\begin{array}{l}78.92 \pm \\
2.69 \mathrm{e}^{-}\end{array}$ & $\begin{array}{l}27.79 \pm \\
1.43^{a}\end{array}$ \\
\hline \multirow[t]{4}{*}{$\begin{array}{l}\text { Xylose } \\
\text { concentration (\%) }\end{array}$} & Xyl 1 & $\begin{array}{l}57.58 \pm \\
2.34^{\mathrm{a}}\end{array}$ & $\begin{array}{l}49.55 \pm \\
1.62^{d}\end{array}$ & $\begin{array}{l}52.98 \pm \\
4.00^{c}\end{array}$ & $\begin{array}{l}46.86 \pm \\
3.09 \mathrm{a}^{\mathrm{a}}\end{array}$ & $\begin{array}{l}72.61^{ \pm} \\
1.81^{c}\end{array}$ \\
\hline & $\mathrm{Xyl} 2$ & $\begin{array}{l}76.98 \pm \\
2.45^{b}\end{array}$ & $\begin{array}{l}20.00 \pm \\
3.15^{c}\end{array}$ & $\begin{array}{l}35.49 \pm \\
3.48^{\mathrm{b}}\end{array}$ & $\begin{array}{l}60.71 \pm \\
1.48^{b}\end{array}$ & $\begin{array}{l}40.74 \pm \\
4.57^{b}\end{array}$ \\
\hline & Xyl 3 & $\begin{array}{l}88.32 \pm \\
1.48^{c}\end{array}$ & $\begin{array}{l}5.08 \pm 1.66 \\
a\end{array}$ & $\begin{array}{l}30.56 \pm \\
0.91^{a}\end{array}$ & $\begin{array}{l}80.52 \pm \\
3.30^{c}\end{array}$ & $\begin{array}{l}31.01 \pm \\
0.63^{a}\end{array}$ \\
\hline & Xyl 4 & $\begin{array}{l}88.34 \pm \\
1.34^{c}\end{array}$ & $\begin{array}{l}3.83 \pm 0.55 \\
a\end{array}$ & $\begin{array}{l}31.22 \pm \\
0.30^{a}\end{array}$ & $\begin{array}{l}83.01 \pm \\
1.07^{c}\end{array}$ & $\begin{array}{l}31.46 \pm \\
0.23^{a}\end{array}$ \\
\hline
\end{tabular}

WBH wheat bran hydrolysate, Glu glucose, Fru fructose, Lac lactose, Mal maltose, Suc sucrose, $X y /$ xylose.

The concentration of carbon sources were $1 \%$ and xylose was $1-4 \%$ in the $\mathrm{WBH}$ medium.

The mean values within the column with different superscript were significantly $(P<0.05)$ different

\subsection{Supplementation of Carbon source to WBH}

Carbon source type had a significant effect on $\mathrm{pH}$, biomass and pigment yield as shown in Fig. 1. The pH of the fermented broth was in the range of 4.5 to 6.5 . The higher biomass observed in the fructose (1.55 $\pm 0.13 \mathrm{gm}$ ) containing media compared to other sugars. Whereas the significant increase in the pigment $(0.945 \pm 0.14 \mathrm{OD}$ units $/ \mathrm{ml})$ production was observed in the xylose medium (Fig. 1A and B). While there was no significant difference in the pigment production in other carbon containing medium (Fig. 1A). Similarly, the highest redness $a \square$ value was found in basal medium supplemented with $1 \%$ xylose (49.55 
$\pm 1.62)$, whereas the least was in sucrose $(5.30 \pm 1.13)$. The production of pigments by $T$. amestolkiae DPUA 1275 was explained utilizing glucose as carbon source and careful selection of nitrogen source [32]. Carbon source addition (glucose, fructose, sucrose, xylose, maltose, and lactose) to the WBH basal medium produced a significant increase in both pigment and biomass yield (Table 1). While the biomass yield in the basal medium containing the carbon sources, except xylose $(1.090 \pm 0.14)$ was significantly higher than the basal medium $(1.044 \pm 0.05)$ alone, but with higher pigment yields. It is due to the fact that simple sugars have induced more of the growth and inhibited the secondary metabolite production [17]. In all the fermented broth containing different carbon source, the $L^{*}, a^{\star}$, and $b^{\star}$ values were positive, indicating yellowness and redness hue (Table 1 and Fig S4). The lightness values were in the range of $70-78$. The hue angle of the pigment produced was in the range of $66-78^{\circ}$ indicating the minor shade changes in the red colour characteristics of the pigment (Table 1). But the significant difference was observed in the chroma value of the pigment produced in the medium containing xylose $(72.61 \pm 1.81)$. This revealed the saturation intensity of the pigment produced in the $1 \%$ xylose medium (Table 1 ) and correlated with the UV-visible spectrum colour appearance in the culture flask (Fig S4).

\subsection{Supplementation of Xylose to WBH}

Since $1 \%$ xylose has significantly induced the pigment production, further to observe the effect of higher concentration of xylose, the concentration was gradually increased to $4 \%$. The results indicated that the increased concentration of xylose was inversely proportional to the pigment production (Fig. 1B). One gram of xylose has shown significant increase in red pigment production in the medium $(49.55 \pm 2.29)$ and least in $4 \mathrm{~g} x y$ lose composition $(3.83 \pm 0.78)$. Similar results were reported that higher concentration of xylose did not induce the pigment production in $T$. atroroseus $\mathrm{GH} 2$ utilising the corn cob hydrolysate [16]. However, the higher concentration of xylose has positively affected the growth of fungus (Fig. 1B). The biomass yield was highest in $4 \mathrm{~g}$ xylose composition $(1.450 \pm 0.16)$, whereas the least biomass yield was in $1 \mathrm{~g}$ xylose composition $(0.915 \pm 0.03)$. The medium containing $1 \mathrm{~g}$ of xylose has shown maximum absorbance $(1.565 \pm 0.07)$ at $494 \mathrm{~nm}$ indicated the higher pigment yield while less pigment yield was observed in the medium containing $4 \mathrm{~g}$ xylose (Fig S5).

It was also observed that the colour characteristics of the pigments was significantly affected by varying xylose $(1-4 \%)$ concentration. Even though the $L^{*}, a^{*}$, and $b^{\star}$ values were positive, indicating yellowness and redness (Table 1). The $a \square$ value (redness), 50 to 4 and chroma intensity, 73 to 32 was significantly decreased and inversely proportional to the xylose concentration (Table 1). The increase in $b \square$ value (yellowness), 31 to 53 and hue angle $47^{\circ}$ to $83^{\circ}$ towards $90^{\circ}$ indicted that, higher concentration of xylose induced yellow pigment production.

Considering the utilization of carbon source, the cultivation of Corydopsis militaris strain TBRC6039 demonstrated that although xylose was less favourable than glucose or sucrose in terms of biomass productivity, this particular strain could efficiently metabolize xylose. Further analyses of key metabolites showed that a high production yield of cordycepin was obtained when it was grown in xylose rather than in favourable carbon sources. Similarly, it was also observed in T. purpureogenus CFRM02 that contain 
alternative gene(s)/pathway(s) for metabolizing xylose. Therefore, most of the assimilated xylose in this strain might be channeled towards the biosynthetic pathway of pigment rather than towards central carbon metabolism [24].

\subsection{Supplementation of nitrogen to WBH}

It was reported that the red pigment produced by Talaromyces are similar to Monascus purpureus pigments. The yield and characteristics of the pigments were affected by the nitrogen source in the growth medium $[4,14]$. Accordingly, the effect of nitrogen source was evaluated. The $\mathrm{pH}$ of the fermented medium was in the range of $5-7$. The individual nitrogen source added to the basal medium significantly affected the yield of biomass. No significant changes in the pigment production was observed (Fig. 1C). The significant increase in the biomass was observed in the medium containing $\mathrm{NaNO}_{3}(2.591 \pm$ $0.59 \mathrm{~g} / 100 \mathrm{ml}$ ) compared other nitrogen sources. The biomass yield was less in the medium containing peptone and $\mathrm{NH}_{4} \mathrm{NO}_{3}$. While the yeast extract positively influenced the biomass yield (2.078 \pm $0.20 \mathrm{gm} / 100 \mathrm{ml})$. Even though the biomass yield was significantly affected by type of nitrogen sources, the pigment production in all the nitrogen containing medium (inorganic or organic), remained almost same (Fig. 1C). Similar type of behaviour was observed by Penicillium sp for pigment production utilising waste stream cellulose as culture medium [27]. The nitrogen sources added individually to the medium did not affect the colour characteristics (Table 2). In all the fermented broth containing different nitrogen source, the $L^{*}, a^{\star}$, and $b^{*}$ values were positive, indicating yellowness and redness (Table 2 ). The lightness values were 85 to 88 . The hue angle of the pigment produced in the medium was in the range of 74 to $84^{\circ}$ indicating the minor shade changes in the red colour characteristics of the pigment (Table 2). Whereas the chroma value was ranging from 28 to 36 . 
Table 2

Effect of nitrogen concentration supplementation to WBH medium on T. purpureogenus CFRM02 pigment characteristics and the CIELAB value.

\begin{tabular}{|c|c|c|c|c|c|c|}
\hline & & $\angle$ lightness & a value & $b$ value & $\begin{array}{l}h \text { hue } \\
\text { angle }\end{array}$ & c chroma \\
\hline & WBH & $\begin{array}{l}85.24 \pm \\
2.33^{b}\end{array}$ & $\begin{array}{l}6.82 \pm \\
2.03^{c}\end{array}$ & $\begin{array}{l}28.16 \pm \\
1.67 \mathrm{ab}\end{array}$ & $\begin{array}{l}76.27 \pm \\
4.64^{a}\end{array}$ & $\begin{array}{l}29.03 \pm \\
1.17 \mathrm{ab}\end{array}$ \\
\hline \multirow[t]{5}{*}{$\begin{array}{l}\text { Nitrogen } \\
\text { source }\end{array}$} & $\mathrm{KNO}_{3}$ & $\begin{array}{l}84.91 \pm \\
0.92^{b}\end{array}$ & $\begin{array}{l}4.30 \pm \\
0.88^{a b}\end{array}$ & $\begin{array}{l}30.04 \pm \\
1.43 \mathrm{ab}\end{array}$ & $\begin{array}{l}81.81 \pm \\
1.94^{b}\end{array}$ & $\begin{array}{l}30.36 \pm \\
1.32 \mathrm{ab}\end{array}$ \\
\hline & $\mathrm{NH}_{4} \mathrm{NO}_{3}$ & $\begin{array}{l}85.26 \pm \\
1.46^{b}\end{array}$ & $\begin{array}{l}3.60 \pm \\
0.47^{a}\end{array}$ & $\begin{array}{l}27.36 \pm \\
1.43^{a}\end{array}$ & $\begin{array}{l}82.48 \pm \\
1.17^{b}\end{array}$ & $\begin{array}{l}27.60 \pm \\
1.39 a^{a}\end{array}$ \\
\hline & $\mathrm{NaNO}_{3}$ & $\begin{array}{l}87.82 \pm \\
1.71 \mathrm{bc}\end{array}$ & $\begin{array}{l}3.49 \pm \\
0.43^{a}\end{array}$ & $\begin{array}{l}30.69 \pm \\
1.82^{b}\end{array}$ & $\begin{array}{l}83.49 \pm \\
0.96^{b}\end{array}$ & $\begin{array}{l}30.89 \pm \\
1.79^{b}\end{array}$ \\
\hline & PEP & $\begin{array}{l}88.87 \pm \\
1.81^{c}\end{array}$ & $\begin{array}{l}4.44 \pm \\
2.66^{a b}\end{array}$ & $\begin{array}{l}35.60 \pm \\
1.91^{c}\end{array}$ & $\begin{array}{l}82.93 \pm \\
4.19^{b}\end{array}$ & $\begin{array}{l}35.94 \pm \\
1.97^{c}\end{array}$ \\
\hline & YE & $\begin{array}{l}81.69 \pm \\
2.06^{a}\end{array}$ & $\begin{array}{l}7.99 \pm \\
0.61^{c}\end{array}$ & $\begin{array}{l}27.11 \pm \\
1.50^{a}\end{array}$ & $\begin{array}{l}73.53 \pm \\
1.72^{a}\end{array}$ & $\begin{array}{l}28.27 \pm \\
1.37^{\mathrm{a}}\end{array}$ \\
\hline \multirow[t]{4}{*}{$\begin{array}{l}\text { Nitrogen } \\
\text { concentration }\end{array}$} & $\mathrm{N} 1$ & $\begin{array}{l}68.28 \pm \\
1.55^{b}\end{array}$ & $\begin{array}{l}13.10 \pm \\
1.25^{\mathrm{a}}\end{array}$ & $\begin{array}{l}71.87 \pm \\
2.06^{a}\end{array}$ & $\begin{array}{l}79.65 \pm \\
1.25^{c}\end{array}$ & $\begin{array}{l}73.06 \pm \\
1.80^{a}\end{array}$ \\
\hline & N2 & $\begin{array}{l}66.17 \pm \\
2.80^{b}\end{array}$ & $\begin{array}{l}18.90 \pm \\
2.04^{b}\end{array}$ & $\begin{array}{l}78.25 \pm \\
0.41^{b}\end{array}$ & $\begin{array}{l}76.43 \pm \\
1.34 \mathrm{bc}\end{array}$ & $\begin{array}{l}80.51 \pm \\
0.87^{b}\end{array}$ \\
\hline & N3 & $\begin{array}{l}59.16 \pm \\
0.69 \text { a }\end{array}$ & $\begin{array}{l}24.45 \pm \\
0.56^{c}\end{array}$ & $\begin{array}{l}81.40 \pm \\
1.54^{c}\end{array}$ & $\begin{array}{l}73.27 \pm \\
0.66^{a b}\end{array}$ & $\begin{array}{l}84.99 \pm \\
1.31^{\mathrm{c}}\end{array}$ \\
\hline & N4 & $\begin{array}{l}59.29 \pm \\
1.40^{a}\end{array}$ & $\begin{array}{l}26.95 \pm \\
2.90^{c}\end{array}$ & $\begin{array}{l}82.80 \pm \\
1.51^{\mathrm{c}}\end{array}$ & $\begin{array}{l}72.00 \pm \\
1.51^{\mathrm{a}}\end{array}$ & $\begin{array}{l}87.10 \pm \\
2.33^{c}\end{array}$ \\
\hline
\end{tabular}

WBH wheat bran hydrolysate, Pep peptone, YE yeast extract

The concentration of nitrogen sources were $0.3 \%$ and $\mathrm{N} 1=0.3 \% \mathrm{YE}, 0.4 \% \mathrm{KNO}_{3}, 0.3 \% \mathrm{NaNO}_{3}, \mathrm{~N} 2=\mathrm{N} 1$ $X 2, N 3=N 1 \times 3$ and $N 4=N 1 \times 4$ in the WBH medium.

The mean values within the column with different superscript were significantly $(P<0.05)$ different.

\subsection{Supplementation $\mathrm{NaNO}_{3}$ and yeast extract to WBH}

Since $\mathrm{NaNO}_{3}$ and yeast extract have positively affected the growth, these two nitrogen source were selected for further process of pigment production along with $\mathrm{KNO}_{3}$ for potassium ion. Interestingly, the pigment production was increased, when these nitrogen sources were added to the medium (Fig. 1D). Further, significant increase in biomass and pigment yield was also observed by increasing the concentration of these nitrogen $(0.3-0.12 \%)$ sources (Fig. 1D). The nitrogen sources added to the 
medium influenced colour characteristics of the pigment. In all the fermented broth containing different nitrogen source, the $L^{*}, a^{*}$, and $b^{\star}$ values were positive, indicating yellowness and redness (Table 2 ). Whereas the $b^{\star}$ values (71 to 83 ) were higher compared to $a^{*}$ values (13 to 27 ). These results indicted the nitrogen sources influence more yellow pigment production compared carbon sources (Table 2). There was significant changes in the colour characteristics of the pigment as the nitrogen concentration increased from $1 X$ to $4 X$. The lightness values ranged from 59 to 68 . The hue angle was ranging from $72^{\circ}$ to $80^{\circ}$ indicating production of orangish red colour characteristic (Table 2).

\subsection{Combined effect of carbon and nitrogen}

It was reported earlier that, the type of pigment or hue produced by ascomycetous filamentous fungi might vary within the same species by growing in different media [9]. Herein also, the culture medium influenced the pigment yield and characteristics of T. purpureogenus CFRM02. Hence, the sixteen different WBH medium were prepared for the cultivation of T. purpureogenus CFRM02 by addition of carbon and nitrogen (Fig S6). Fermentation broths were used for pigment estimation and analysis of colour characteristics. Interestingly it was observed that, the significant increase in the higher pigment production in the medium containing high xylose concentration (Fig. 2). Whereas, the production of pigment was higher in the WBH medium containing $1 \%$ xylose only (Fig. 1A and B). Similarly, the biomass yield was more when high concentration of carbon and nitrogen was added to the medium (Fig. 2).

The values of $L^{*}, a^{*}$, and $b^{*}$ were all positive, indicating yellowness and redness (Table 3 ). The significant difference was observed in the $L^{*}, a^{*}$, and $b^{*}$ values. The lightness values were ranging from $52-80$. The $a^{*}$ values were ranging from 7 to 33 indicating the light red to middle red intensity. The $b^{\star}$ values were ranging from 41 to 75 indicating middle reddish-orange to deep reddish-orange pigment. The $a^{\star}$ value was higher $(33 \pm 3)$ in the medium containing $1-2 \%$ carbon and nitrogen sources as presented in Table 3 . While the hue angle was ranging from $65^{\circ}$ to $82^{\circ}$ corresponding to light red and middle orange. This indicated changes in the hue of the pigment produced from red to orange to yellow in the culture medium of the T. puprureuogenus CFRM02. The chroma values varied in a range from 42 (gray) to 78 (bright) according to the medium used for cultivation. On the basis of the hue angle and chroma values the pigments derived with carbon and nitrogen source had various shades of red. The higher chroma values were observed in the higher concentration of the xylose suggested the brightest colour hue. These results suggested that, higher chroma values can be observed by increasing the concentration of the xylose (Table 3). The colours varied according to the concentration of the carbon and nitrogen source used in the fermentation medium.

Studies have reported that organic nitrogen sources are better than inorganic ones to promote pigment production by Talaromyces/Penicillium [32]. However, in this study, significant changes were not observed in the pigment production and colour characteristics when supplemented with organic and inorganic nitrogen (Table 2). There are not more data on the CIE Lab colour characteristics of $T$. purpureogenus CFRM02 especially from the prospective of food use. Moreover, our previous studies on the toxicity evaluation of the T. purpureogenus CFRM02 pigment confirmed its nontoxic effect [21, 22]. The color hues of T. purpureogenus CFRM02 pigment was similar to color hues of the red and orange 
Monascus pigments [14]. This signifies the contribution of the present findings and the reddish-orange hues of T. purpureogenus CFRM02 pigments can be worth to consider in food use.

Table 3

The combined effect of carbon and nitrogen concentration supplementation to WBH medium on $T$. purpureogenus CFRM02 pigment characteristics and the CIELAB value.

\begin{tabular}{|c|c|c|c|c|c|}
\hline & $\angle$ lightness & a value & $b$ value & $h$ hue angle & c chroma \\
\hline N1C1 & $80.13 \pm 1.39^{j}$ & $8.63 \pm 1.11^{\mathrm{a}}$ & $42.05 \pm 1.61^{a}$ & $1.02^{\mathrm{fgh}}$ & $42.93 \pm 1.79^{a}$ \\
\hline $\mathrm{N} 1 \mathrm{C} 2$ & $78.96 \pm 1.02 \mathrm{ij}$ & $14.56 \pm 1.08^{b}$ & $41.11 \pm 1.66^{a}$ & $70.51 \pm 0.61^{b}$ & $43.61 \pm 1.92^{\mathrm{a}}$ \\
\hline N1C3 & $60.63 \pm 7.24$ cde & $30.44 \pm 1.81^{d}$ & $67.09 \pm 1.76$ def & $65.58 \pm 1.85^{a}$ & $73.70 \pm 0.85 \mathrm{de}$ \\
\hline N1C4 & $54.80 \pm 8.05^{\mathrm{abc}}$ & $32.52 \pm 2.85^{d}$ & $70.25 \pm 1.51 \mathrm{fg}$ & $65.16 \pm 2.38^{a}$ & $77.45 \pm 0.17^{e}$ \\
\hline $\mathrm{N} 2 \mathrm{C} 1$ & $72.05 \pm 4.20 \mathrm{ghi}$ & $17.99 \pm 1.33^{c}$ & $40.97 \pm 0.45^{a}$ & $66.30 \pm 1.78^{a}$ & $44.76 \pm 0.12^{a}$ \\
\hline $\mathrm{N} 2 \mathrm{C} 2$ & $80.29 \pm 2.23^{j}$ & $9.07 \pm 0.33^{a}$ & $52.41 \pm 7.33^{b}$ & $80.03 \pm 1.73$ hi & $53.20 \pm 7.16^{b}$ \\
\hline $\mathrm{N} 2 \mathrm{C} 3$ & $61.68 \pm 6.18$ cde & $21.56 \pm 1.80$ & $67.88 \pm 1.08$ def & 72.3 & 71.2 \\
\hline $\mathrm{N} 2 \mathrm{C} 4$ & $49.23 \pm 2.50^{a}$ & $32.49 \pm 2.75^{d}$ & $70.45 \pm 3.87 \mathrm{fg}$ & $65.18 \pm 3.04^{a}$ & $77.65 \pm 2.36^{e}$ \\
\hline N3C1 & $76.40 \pm 2.44$ hij & $12.54 \pm 0.99^{b}$ & $52.32 \pm 5.52^{b}$ & $76.50 \pm 0.35$ defg & $53.80 \pm 5.60^{b}$ \\
\hline N3C2 & $75.30 \pm 1.24 \mathrm{hji}$ & $13.32 \pm 1.31^{b}$ & $55.80 \pm 3.96 \mathrm{bc}$ & $76.59 \pm 0.36$ defg & $57.37 \pm 4.16^{b}$ \\
\hline N3C3 & $69.52 \pm 0.69 \mathrm{fgh}$ & $13.60 \pm 1.96^{b}$ & $62.55 \pm 5.09 \mathrm{de}$ & .70 efg & $64.06 \pm 4.55^{c}$ \\
\hline N3C4 & $51.63 \pm 6.34 \mathrm{ab}$ & $29.82 \pm 4.06^{d}$ & $69.82 \pm 1.84^{\mathrm{fg}}$ & $66.87 \pm 3.35^{a}$ & $76.00 \pm 0.12 \mathrm{de}$ \\
\hline $\mathrm{N} 4 \mathrm{C} 1$ & $76.45 \pm 3.31^{\text {hij }}$ & $7.56 \pm 1.82^{\mathrm{a}}$ & $52.84 \pm 4.03^{b}$ & $81.74 \pm 2.55^{i}$ & $53.41 \pm 3.73^{b}$ \\
\hline $\mathrm{N} 4 \mathrm{C} 2$ & $67.02 \pm 2.82 \mathrm{efg}$ & $18.95 \pm 1.08^{c}$ & $61.61 \pm 3.03^{c d}$ & $72.86 \pm 1.71 \mathrm{bcd}$ & $64.47 \pm 2.57^{c}$ \\
\hline N4C3 & $57.76 \pm 1.98 \mathrm{bcd}$ & $21.57 \pm 1.71^{c}$ & $74.88 \pm 4.06^{g}$ & $73.87 \pm 2.04$ bcde & $77.96 \pm 3.43^{e}$ \\
\hline N4C4 & $63.80 \pm 4.04$ def & $18.39 \pm 2.63^{c}$ & $68.23 \pm 1.46$ ef & $74.90 \pm 2.37$ cdef & $70.71 \pm 0.73^{d}$ \\
\hline
\end{tabular}

The $\mathrm{N}$ and $\mathrm{C}$ corresponds to the nitrogen and carbon at different concentration in the WBH medium.

The $\mathrm{N}$ nitrogen sources, $\mathrm{N} 1=0.3 \% \mathrm{YE}, 0.4 \% \mathrm{KNO}_{3}, 0.3 \% \mathrm{NaNO}_{3}, \mathrm{~N} 2=\mathrm{N} 1 \mathrm{X} 2, \mathrm{~N} 3=\mathrm{N} 1 \mathrm{X} 3$ and $\mathrm{N} 4=\mathrm{N} 1$ $\mathrm{X} 4$.

The C1-C4 corresponds to $1-4 \%$ of xylose concentration.

The mean values within the column with different superscript were significantly $(P<0.05)$ different. 


\section{Conclusions}

This study showed the promising use of WHB for the production of pigments by T. purpureogenus CFRM02. The WBH supplemented with xylose (1\%) was the best medium for pigment production, comparable to the obtained with a synthetic medium. Whereas, the colour characteristics with the WBH medium differed from the medium used as a control. In general, the evidence from this study validates that carbon and nitrogen composition significantly affects the microorganism growth and the pigments production by $T$. purpureogenus CFRM02. Characterization of agro-industrial wastes is crucial in order to induce the microorganism's secondary metabolism and to control the pigmented molecules production. The ability of $T$. purpureogenus CFRM02 to grow and produce pigments using WBH medium makes it a promising and economically competitive for large-scale fermentation process.

\section{Declarations}

\section{Acknowledgement}

We express sincere thanks to Director, CSIR-Central Food Technological Research Institute, Mysore, India for constant encouragement and providing the facility to carry out the work. SGP acknowledge to Indian Council of Medical Research (ICMR), New Delhi, for the award of Research Fellowship.

\section{Competing interests}

All the authors declare that they have no competing interests.

\section{Authors' contributions}

SD and SGP executed experiment, biological assay and analysis of the data. MD and MK designed the experiment, interpretation of results and wrote the manuscript. All the authors read and approved the final manuscript.

\section{References}

1. Aruldass CA, Dufossé L, Ahmad WA (2018) Current perspective of yellowish-orange pigments from microorganisms- a review. J Clean Prod 180:168-182

2. Dhale MA, Vijay-Raj AS (2009) Pigment and amylase production in Penicillium sp NIOM-02 and its radical scavenging activity. Int J Food Sci Technol 44:2424-2430

3. Dhale MA, Vijay-Raj AS (2009) Pigment and amylase production in Penicillium sp NIOM-02 and its radical scavenging activity. International Journal of Food Science Technology 44:2424-2430

4. Dhale MA, Mohan-Kumari HP (2014) A comparative rapid and sensitive method to screen Lasparaginase producing fungi. J Microbiol Methods 102:66-68

5. Dufossé L (2006) Microbial Production of Food Grade Pigments. Food Technology Biotehnology 44:313-321 
6. Dufossé L, Fouillaud M, Caro Y, Mapari SAS, Sutthiwong N (2014) Filamentous fungi are large-scale producers of pigments and colorants for the food industry. Curr Opin Biotechnol 26:56-61

7. Duran N, Teixeira MF, De Conti R, Esposito E (2002) Ecological-friendly pigments from fungi. Critical Reviews in Food Science and Nutrition:53-66

8. Hernández VA, Galleguillos F, Thibaut R, Müller A (2019) Fungal dyes for textile applications: testing of industrial conditions for wool fabrics dyeing. Journal of Textile Inststitute 110:61-66

9. Jung H, Kim C, Kim K, Shin CS (2003) Color characteristics of Monascus pigments derived by fermentation with various amino acids. Journal of Agriculture Food Chemistry 51:1302-1306

10. Kantifedaki A, Kachrimanidou V, Mallouchos A, Papanikolaou S, Koutinas AA (2018) Orange processing waste valorisation for the production of bio-based pigments using the fungal strains Monascus purpureus and Penicillium purpurogenum. J Clean Prod 185:882-890

11. Lagashetti AC, Dufossé L, Singh SK, Singh PN (2019) Fungal pigments and their prospects in different industries. Microorganisms 7:604

12. Liu J, Guo T, Luo Y (2019) Enhancement of Monascus pigment productivity via a simultaneous fermentation process and separation system using immobilized-cell fermentation. Biores Technol 272:552-560

13. Mapari SA, Thrane U, Meyer AS (2010) Fungal polyketide azaphilone pigments as future natural food colorants? Trends Biotechnol 28:300-307

14. Mapari SAS, Meyer AS, Thrane U (2006) Colorimetric characterization for comparative analysis of fungal pigments and natural food colorants. Journal of Agriculture Food Chemistry 54:7027-7035

15. Mapari SAS, Meyer AS, Thrane U, Frisvad JC (2009) Identification of potentially safe promising fungal cell factories for the production of polyketide natural food colorants using chemotaxonomic rationale. Microb Cell Fact 8:24

16. Morales-Oyervides L, Ruiz-S'anchez JP, Oliveira JC, Sousa-Gallagher MJ, Morales-Mart'ınez TK, Albergamo A, Salvo A, Giuffrida D, Dufoss'e L, Monta nez J (2020) Medium design from corncob hydrolyzate for pigment production by Talaromyces atroroseus GH2: Kinetics modeling and pigments characterization. Biochemical Engineering Journal

17. Morales-Oyervides L, Ruiz-Sánchez JP, Oliveira JC, Sousa-Gallagher MJ, Méndez-Zavala A, Giuffrida D, Dufossé L, Montañez J (2020) Biotechnological approaches for the production of natural colorants by Talaromyces/Penicillium: A review. Biotechnology Advances

18. Mussatto SI, Teixeira JA, Ballesteros LF, Martins S (2012) Use of agro-industrial wastes in solid-state fermentation processes. InTech, Shanghai

19. Panagiotou G, Olsson $L$ (2007) Effect of compounds released during pretreatment of wheat straw on microbial growth and enzymatic hydrolysis rates. Biotechnol Bioeng 96:250-258

20. Pandit SG, Puttananjaiah MH, Harohally NV, Dhale MA (2018) Functional attributes of a new molecule-2-hydroxymethyl-benzoic acid 2'-hydroxy-tetradecyl ester isolated from Talaromyces purpureogenus CFRM02. Food Chem 255:89-96 
21. Pandit SG, Krishna PMR, Puttananjaiah MH, Dhale MA (2019) Cicer arietinum (Bengal gram) husk as alternative for Talaromyces purpureogenus CFRM02 pigment production: Bioactivities and identification. LWT-Food Science and Tecnnology, p 108499

22. Pandit SG, Puttananjaiah MH, Muthukumar SP, Dhale MA (2020) Safety efficacy and chemical profiling of water-soluble Talaromyces purpureogenus CFRM02 pigment. Food Chem 310:125869

23. Panesar R, Kaur S, Panesar PS (2015) Production of microbial pigments utilizing agro-industrial waste: a review. Current Opinion in Food Science 1:70-76

24. Raethong N, Laoteng K, Vongsangna W (2018) Uncovering global metabolic response to cordycepin production in Cordyceps militaris through transcriptome and genome-scale network-driven analysis. Sci Rep 8:9250

25. Santos-Ebinuma VC, Roberto IC, Simas-Teixeira MF, Pessoa A (2013) Improving of red colorants production by a new Penicillium purpurogenum strain in submerged culture and the effect of different parameters in their stability. Biotechnol Prog 29:778-785

26. Si D, Shanga T, Liua X, Zhenga Z, Hua Q, Hua C, Zhanga R (2020) Production and characterization of functional wheat bran hydrolysate rich in reducing sugars, xylooligosaccharides and phenolic acids. Biotechnology Reports 27:e00511

27. Sopandi T, Wardah A, Surtiningsih T, Suwandi A, Smith JJ (2013) Utilization and optimization of a waste stream cellulose culture medium for pigment production by Penicillium spp. J Appl Microbiol 114:733-745

28. Tuli HS, Chaudhary P, Beniwal V, Sharma AK (2014) Microbial pigments as natural color sources: current trends and future perspectives. J Food Sci Technol 52:1-10

29. Venil CK, Zakaria ZA, Ahmad WA (2013) Bacterial pigments and their applications. Process Biochem 48:1065-1079

30. Venkatachalam M, Gérard L, Milhau F, Vinale F, Dufossé L, Fouillaud M (2019) Salinity and temperature influence growth and pigment production in the marine-derived fungal strain Talaromyces albobiverticillius. Microorganisms 7:10

31. Yilmaz N, Houbraken J, Hoekstra ES, Frisvad JC, Visagie CM, Samson RA (2012) Delimitation and characterisation of Talaromyces purpurogenus and related species. Persoonia-Molecular Phylogeny Evolution of Fungi 29:39-54

32. Zaccarim BR, de Oliveira F, Passarini MRZ, Duarte AWF, Sette LD, Jozala AF, Teixeira MFS, de Carvalho Santos-Ebinuma V (2019) Sequencing and phylogenetic analyses of Talaromyces amestolkiae from amazon: A producer of natural colorants. Biotechnol Prog 35:e2684

\section{Figures}



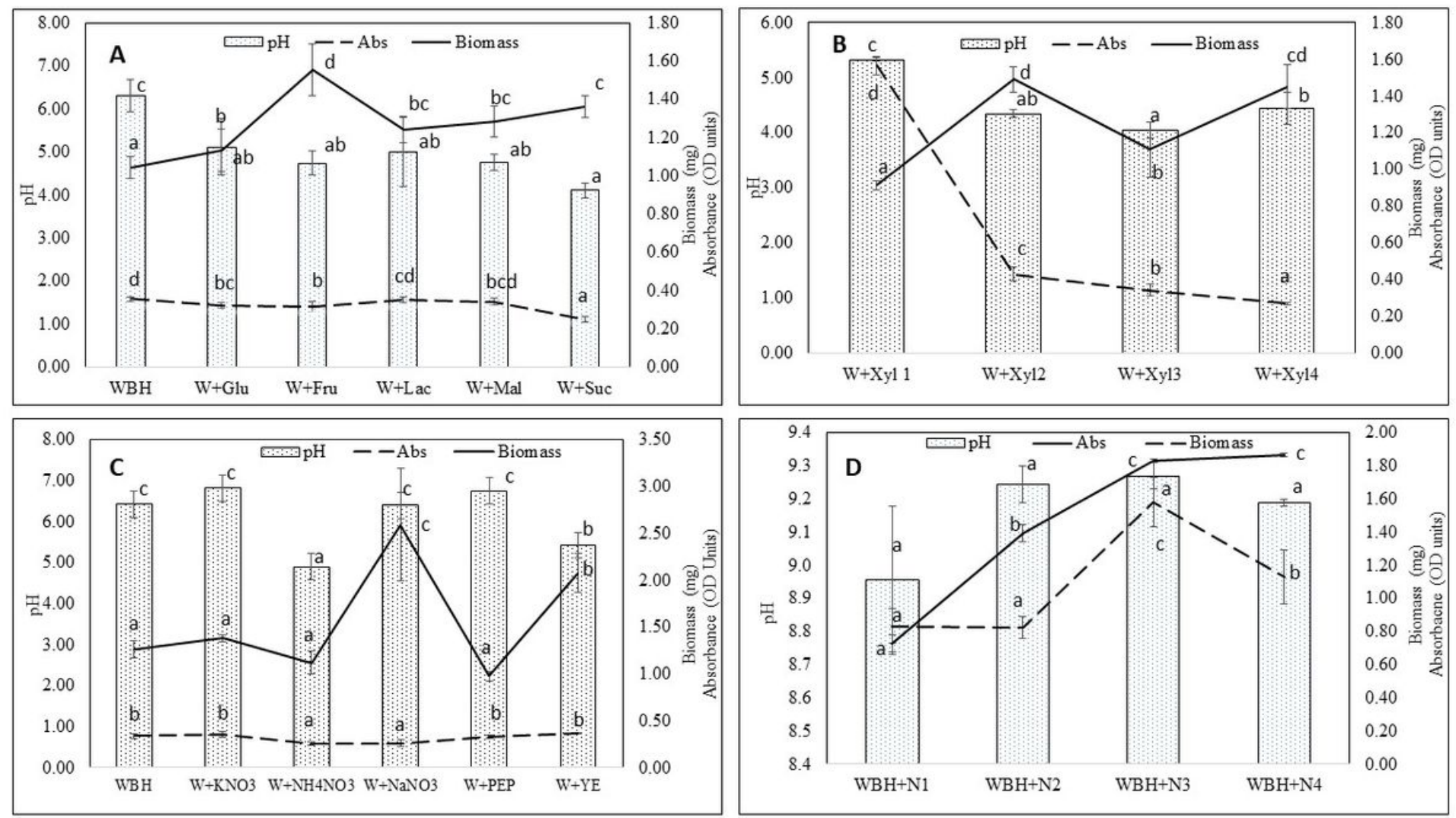

\section{Figure 1}

Effect of carbon sources (A), xylose (B), nitrogen sources (C) and combination of carbon and nitrogen (D) on the $\mathrm{pH}$, pigment and biomass production. WBH (W) wheat bran hydrolysate, Glu glucose, Fru fructose, Lac lactose, Mal maltose, Suc sucrose, Xyl xylose, Pep peptone, YE yeast extract. The nitrogen and carbon source at different concentration in the WBH medium. The $\mathrm{N}$ nitrogen sources, $\mathrm{N} 1=0.3 \% \mathrm{YE}, 0.4 \%$ $\mathrm{KNO} 3,0.3 \% \mathrm{NaNO}, \mathrm{N} 2=\mathrm{N} 1 \times 2, \mathrm{~N} 3=\mathrm{N} 1 \times 3$ and N4= N1 X 4 in the WBH medium. The Xyl1-4 corresponds to $1-4 \%$ of xylose concentration in the WBH medium. The mean values within the bar and lines with different superscript were significantly $(P<0.05)$ different. 


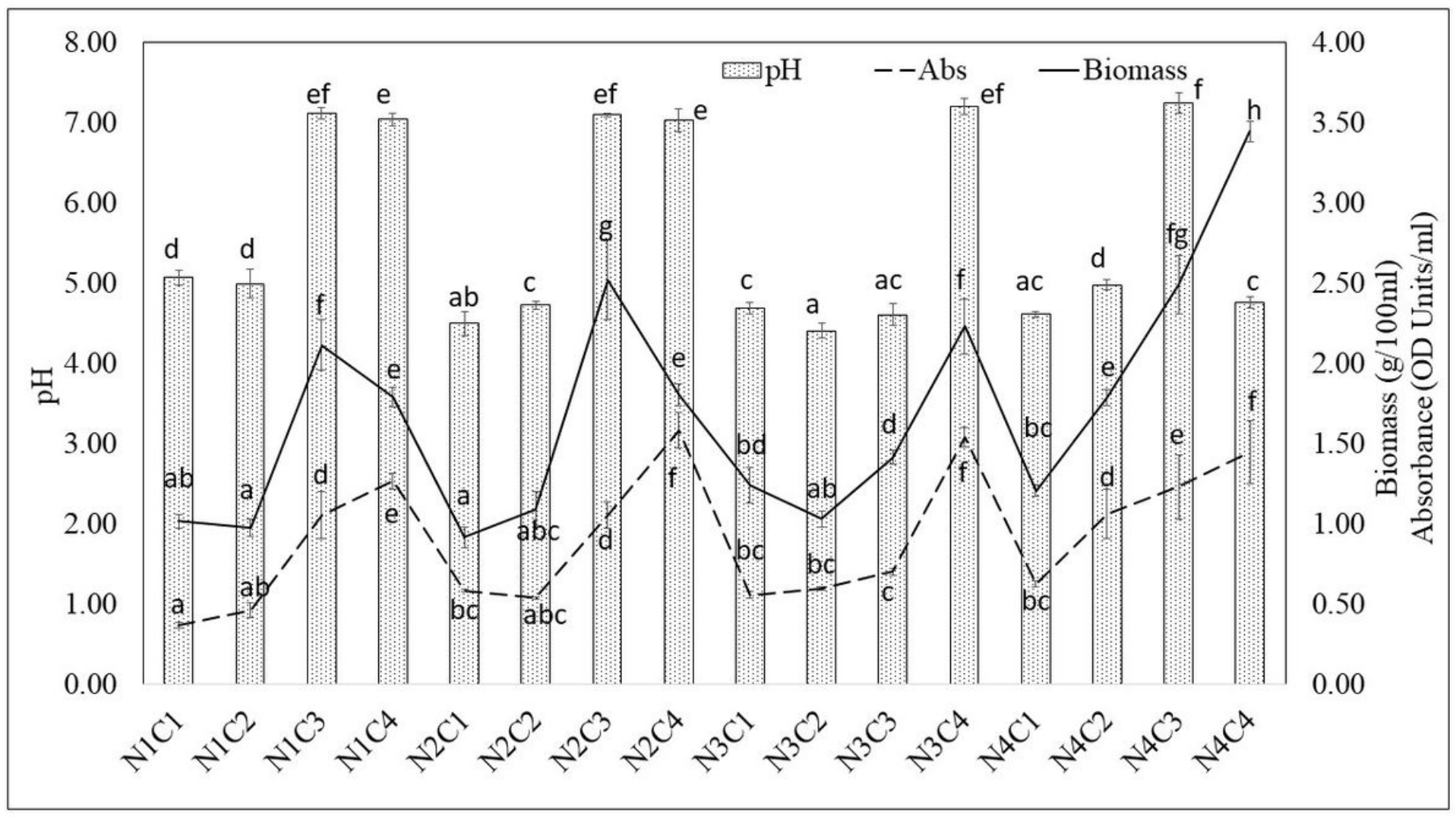

Figure 2

Effect of the concentration of xylose (1-4\%) and combination of nitrogen sources on the $\mathrm{pH}$, pigment and biomass production. The $\mathrm{N}$ and $\mathrm{C}$ corresponds to the nitrogen and carbon at different concentration in the WBH medium. The $\mathrm{N}$ nitrogen sources, $\mathrm{N} 1=0.3 \% \mathrm{YE}, 0.4 \% \mathrm{KNO}, 0.3 \% \mathrm{NaNO} 3, \mathrm{~N} 2=\mathrm{N} 1 \times 2, \mathrm{~N} 3=\mathrm{N} 1 \times 3$ and N4= N1 X 4. The C1-C4 corresponds to $1-4 \%$ of xylose concentration. The mean values within the bar and lines with different superscript were significantly $(P<0.05)$ different.

\section{Supplementary Files}

This is a list of supplementary files associated with this preprint. Click to download.

- Supplimentaryfigures.docx 